\title{
The difference effect of estrogen on muscle tone of medial and lateral thigh muscle during ovulation
}

\author{
Eun-Sook Sung', Jung-Hyun Kim ${ }^{2 * *}$ \\ 'Department of Sports Rehabilitation, College of Health Welfare, Woosong University, Daejeon, Korea \\ 2Department of Physical Therapy, College of Health Welfare, Woosong University, Daejeon, Korea
}

The purpose of this study was to investigate the difference effect of estrogen on muscle tone of medial and lateral thigh muscle during ovulation (OV). Twenty-eight untrained eumenorrheic healthy women tested muscle stiffness and frequency of vastus medialis, vastus lateralis, semitendinosus, and biceps femoris during menstrual cycle (MC). MC were divided into menses (MS), OV, and luteal phase (LP). The muscle frequency of vastus medialis and semitendinosus were significant higher in OV $(13.83 \pm 1.58 \mathrm{~Hz}, 15.62 \pm 2.39 \mathrm{~Hz})$ than $\mathrm{LP}(13.18 \pm 0.85 \mathrm{~Hz}, 14.67 \pm$ $1.62 \mathrm{~Hz}$ ). Also the muscle stiffness of vastus medialis and semitendino-

\section{INTRODUCTION}

Female athletes have elevated a risk of suffering musculoskeletal and anterior cruciate ligament (ACL) injuries compared with males that participate in the same sport (Arendt et al., 1999). The possible explanations include gender related differences in physiological and physical factors, i.e., hormones, ligament size, coordination, training, strength, endurance, anatomy, and muscle fiber composition (Costill et al., 1976; Lebrun, 1994; Prince et al., 1977; Schantz et al., 1983). One of the different factor by female is regular hormone fluctuation during the menstrual cycle (MC) and the ovarian hormones, such as estrogen and progesterone, are known to have a noticeable influence on protein metabolism at rest and during exercise (Oosthuyse and Bosch, 2010) and to affect the composition and structure of a variety of tissues (Lebrun, 1994). Previous studies reported sex steroid hormones have been shown to influence collagen, tendon and ligament (Dyer et al., 1980; Fischer, 1973; Fischer and Swain, 1977; Hama et al., 1976) and maximum muscle force (Sung et al., 2014). Especially, in- sus were significant higher in OV $(211.74 \pm 46.03 \mathrm{~N} / \mathrm{m}, 241.95 \pm 48.35 \mathrm{~N} / \mathrm{m})$ than $L P(184.26 \pm 26.09 \mathrm{~N} / \mathrm{m}, 215.42 \pm 35.29 \mathrm{~N} / \mathrm{m})$. The present study showed the highest muscle stiffness and frequency at $\mathrm{OV}$ and this might be due to the rapid increase of sole hormone in estrogen. Especially, medial part of quadriceps and hamstrings might be influenced during the MC with high concentration of estrogen at $\mathrm{OV}$.

Keywords: Estrogen, Menstrual cycle, Muscle tonus, Ovulation
${ }^{*}$ Corresponding author: Jung-Hyun Kim (D) https://orcid.org/0000-0002-4710-8145 Department of Physical Therapy, College of Health Welfare, Woosong University, 171 Dongdaejeon-ro, Dong-gu, Daejeon 34606, Korea

Tel: +82-42-630-4625, Fax +82-42-630-4611, E-mail: junghyunkim9144@gmail.com Received: February 27, 2018 / Accepted: April 10, 2018 creasing concentrations of estrogen had decreased to synthesize type collagen in human ACL tissue (Räsänen and Messner, 2000) and most recent ACL consensus statement concluded that the risk of female's injury is not equal across the MC with the greatest risk during the pre-ovulatory phase (Beynnon and Shultz, 2008). Moreover, estrogen increased the concentration of relaxin receptor in the rat myometrium, thereby enhancing its sensitivity to relaxin (Mercado-Simmen et al., 1982). Further, Yu et al. (2001) reported that dose dependent effect increase in ACL fibroblast proliferation and active synthesis of pro-collagen type 1 was observed, when progesterone concentrations were increased as estrogen concentrations were held constant. At lower concentrations of estrogen 2 (E2), the dose dependent effects of progesterone were more pronounced than at the higher estrogen concentrations. This phenomenon again confirmed estrogen exerting the more dominant effect (Yu et al., 2001). In addition, Fischer (1973) demonstrated that collagen concentration decreased after treatment with estradiol in rat tail tendon (Fischer, 1973).

These previous studies demonstrated the concentrations of es- 
trogen and progesterone would be influenced the mechanical properties of tendon and ligament. On the other hand, the MC phase does not affect the strength, activation level and twitch properties of human muscle, peak tension of quadriceps femoris muscle (Janse de Jonge et al., 2001; Kubo et al., 2009). However, researchers noted a lack of understanding of which skeletal muscle may affect joint stability. The purpose of this study was to investigate the difference effect of estrogen on muscle tone and the different phenomenon of agonist and antagonist muscle on lateral and medial part during the ovulation (OV).

\section{MATERIALS AND METHODS}

\section{Participants}

Twenty-eight female students were recruited, with a mean age of $20.0 \pm 0.9$ years, height of $162.0 \pm 6.2 \mathrm{~cm}$, weight of $58.6 \pm 7.5$ $\mathrm{kg}$, and body mass index $22.4 \pm 2.8 \mathrm{~kg} / \mathrm{m}^{2}$ (Table 1). The subjects volunteered to participate in this study and were selected from the following inclusion criteria: healthy physical condition female without any neurological or movement disorder, nonsmokers, regular menstruation, no other medications that might interference hormone levels and sedentary or recreationally active. The women entering the study had not been without oral contraceptives for at least one year. All subjects volunteered to participate and gave their written informed consent before the study.

\section{Instruments}

The MyotonPRO (MyotonAS, Estonia and Myoton Ltd., London, England) is placed perpendicular to the skin over the muscle belly being test. The device is used under constant preload ( 0.18 $\mathrm{N})$, to precompress skin, and press a 15 -msec mechanical tap at a pre force $(0.4 \mathrm{~N})$, followed by immediately release. Those damped oscillations are recorded by the testing probe. Nonneural tone and state of tension are measured from signal spectrum Fmax (FFT Fast Fourier Transform). Those results are identified by frequency $(\mathrm{Hz})$ of the pressed oscillations (Pisano et al., 2000). The Myoton-Pro has a high levels of reliability, (Lidstrom et al., 2009) and

Table 1. General characteristics of participants $(n=28)$

\begin{tabular}{lr}
\hline Characteristic & Mean \pm SD \\
\hline Age $(\mathrm{yr})$ & $20.0 \pm 0.9$ \\
Height $(\mathrm{cm})$ & $162.0 \pm 6.2$ \\
Weight $(\mathrm{kg})$ & $58.6 \pm 7.5$ \\
Body mass index $\left(\mathrm{kg} / \mathrm{m}^{2}\right)$ & $22.4 \pm 2.8$ \\
\hline
\end{tabular}

$\mathrm{SD}$, standard deviation. it is shown of good construct validity against maximum voluntary isometric contraction (Zinder and Padua, 2011).

\section{Procedures}

Before starting of training, all subjects measured their basal body temperature to observe regular $\mathrm{MC}$ and this result were used to predict the cycle phases. The subjects measured their basal body temperature orally with a digital thermometer for one minute every morning throughout the entire study period at the same time before getting out of bed. Basal body temperature was suggested as an OV indicator and defined as the low point in the temperature curve seen at the base of the rise to the hyper-thermic phase (de Mouzon et al., 1984). Laboratory is set up 20 degree with using a digital thermometer. Subjects initially lay supine for vastus medialis and vastus lateralis and prone position for semitendinosus and biceps femoris and prevented long-lasting static muscular tension for at least $10 \mathrm{~min}$ prior to the measurement. Room temperature on the thigh was recorded using a digital thermometer. To maintain consistency of measurement between participants and positions, marks were drawn over the skin using a pen to correspond with 4 muscles on dominant leg: vastus medialis, vastus lateralis, semitendinosus, and biceps femoris. Three consecutive tests were measured and taken at each muscle position, giving a mean stiffness and frequency score (Ditroilo et al., 2011). The entire duration of a MC was divided into menses (MS: 5 th day after menstrual bleeding), OV (increase in body temperature of at least $0.3^{\circ} \mathrm{C}$ ), and luteal phase (LP: 7th day after OV). All subjects tested 3 times (MS, OV, and LP) and individually according to own MC.

\section{Statistical analysis}

SPSS ver. 12.0 (SPSS Inc., Chicago, IL, USA) was used for statistical analysis in this study. One-way repeated measure analysis of variance was used to decide the difference effect of estrogen on muscle tone of medial and lateral thigh muscles in MS, OV, and LP during MC. Also Bonferroni post hoc test was applied. A corrected $P$-value was less than 0.05 .

\section{RESULTS}

The muscle frequency of vastus medialis and semitendinosus were significant higher in OV $(13.83 \pm 1.58 \mathrm{~Hz}, 15.62 \pm 2.39 \mathrm{~Hz})$ than $\mathrm{LP}(13.18 \pm 0.85 \mathrm{~Hz}, 14.67 \pm 1.62 \mathrm{~Hz})(P<0.05)$ (Table 2). Also the muscle stiffness of vastus medialis and semitendinosus were significant higher in the OV $(211.74 \pm 46.03 \mathrm{~N} / \mathrm{m}, 241.95 \pm$ 
Table 2. Muscle frequency changes throughout the menstrual cycle

\begin{tabular}{lcccc}
\hline Muscles & $\mathrm{MS}(\mathrm{Hz})$ & $\mathrm{OV}(\mathrm{Hz})$ & $\mathrm{LP}(\mathrm{Hz})$ & $F$ \\
\hline Vastus medialis & $13.52 \pm 1.31$ & $13.83 \pm 1.58^{*}$ & $13.18 \pm 0.85$ & 2.341 \\
Vastus lateralis & $17.39 \pm 2.27$ & $17.36 \pm 2.32$ & $17.66 \pm 2.62$ & 0.170 \\
Semitendinosus & $15.00 \pm 1.76$ & $15.62 \pm 2.39^{*}$ & $14.67 \pm 1.62$ & 2.640 \\
Biceps femoris & $13.96 \pm 1.56$ & $14.07 \pm 1.60$ & $13.94 \pm 1.34$ & 0.111
\end{tabular}

Values are presented as mean \pm standard deviation.

$M S$, menses; OV, ovulation; $L P$, luteal phase.

*Significantly different compared to $L P(P<0.05)$.

$48.35 \mathrm{~N} / \mathrm{m})$ than LP $(184.26 \pm 26.09 \mathrm{~N} / \mathrm{m}, 215.42 \pm 35.29 \mathrm{~N} / \mathrm{m})$ $(P<0.05)$ (Table 3). However we did not find significant different muscle frequency and stiffness of vastus lateralis and biceps femoris between MS, OV, and LP (Tables 2, 3).

\section{DISCUSSION}

The purpose of our study was to determine the differences in muscle frequency and stiffness with estrogen and progesterone fluctuation during a normal 28- to 30-day MC. The MS, OV, and LPs of the MC were identified to establish values for basal temperature. We observed muscle frequency and stiffness of vastus medialis, vastus lateralis, semitendinosus and biceps femoris and the most important finding of the present study was first, the significant higher muscle frequency of vastus medialis in the $\mathrm{OV}$ $(13.83 \pm 1.58 \mathrm{~Hz})$ than $\mathrm{LP}(13.18 \pm 0.85 \mathrm{~Hz})$ and muscle frequency of semitendinosus was significant higher in the OV $(15.62 \pm$ $2.39 \mathrm{~Hz})$ than LP $(14.67 \pm 1.62 \mathrm{~Hz})$. However we did not find significant different muscle frequency of vastus lateralis and biceps femoris in MS, OV, and LP. Secondly, we observed the same aspect like muscle stiffness of vastus medialis and semitendinosus were significant higher in OV $(211.74 \pm 46.03 \mathrm{~N} / \mathrm{m} ; 241.95 \pm$ $48.35 \mathrm{~N} / \mathrm{m})$ than LP $(184.26 \pm 26.09 \mathrm{~N} / \mathrm{m} ; 215.42 \pm 35.29 \mathrm{~N} / \mathrm{m})$. However we did not find significant different muscle frequency of vastus lateralis and biceps femoris in MS, OV and LP. These results of different phase hormone effect are supported by Wilkerson and Mason (2000), muscle stiffness and may be influenced by estrogen fluctuations across the MC (Eiling et al., 2007).

Estrogen and progesterone are lowest during the menstrual phase of the cycle. During the follicular phase, estrogen levels rise dramatically as a result of rising levels of luteinizing hormone, while progesterone remains relatively low. This hormone fluctuation can be influenced greater knee and ankle laxity values in comparison to male subject and hamstring injury is extremely common in female's athletes (Huston and Wojtys, 1996; Wilker-
Table 3. Muscle stiffness changes throughout the menstrual cycle

\begin{tabular}{lcccc}
\hline Muscles & $\mathrm{MS}(\mathrm{N} / \mathrm{m})$ & $\mathrm{OV}(\mathrm{N} / \mathrm{m})$ & $\mathrm{LP}(\mathrm{N} / \mathrm{m})$ & $F$ \\
\hline Vastus medialis & $194.74 \pm 35.00$ & $211.74 \pm 46.03^{*}$ & $184.26 \pm 26.09$ & 3.654 \\
Vastus lateralis & $366.53 \pm 73.65$ & $362.84 \pm 87.88$ & $348.63 \pm 84.36$ & 0.772 \\
Semitendinosus & $229.16 \pm 39.53$ & $241.95 \pm 48.35^{*}$ & $215.42 \pm 35.29$ & 6.863 \\
Biceps femoris & $250.95 \pm 48.40$ & $242.74 \pm 34.59$ & $247.21 \pm 29.78$ & 0.117 \\
\hline
\end{tabular}

Values are presented as mean \pm standard deviation.

MS, menses; OV, ovulation; LP, luteal phase.

${ }^{*}$ Significantly different compared to $\mathrm{LP}(P<0.05)$.

son and Mason, 2000). They reported, muscles stiffness is important to dynamic knee stability during exercise and might be more important to knee stability than muscular strength (Duan et al., 1997; Wagner and Blickhan, 2003). Some studies have reported that the effects of cycling sex hormones on musculoskeletal function and significant slowing of muscle relaxation and an increased muscle fatigability during the ovulatory phase (Sarwar et al., 1996) and muscle stiffness may be influenced by hormonal fluctuations across the MC (Eiling et al., 2007). Estrogen is affected on the growth and development of bone, muscle and connective tissue and influence collagen (Lebrun, 1994) and collagen metabolism in tendon fibroblasts (Irie et al., 2010). Like previous study, our results of muscle stiffness and muscle frequency were influenced with hormone fluctuation, especially, we found significant different just medial part of muscles. The medial part of the representative agonist and antagonist muscles showed the highest muscle stiffness and frequency at $\mathrm{OV}$ and the lowest muscle stiffness and frequency at LP. This may be due to the rapid increase of sole hormone in estrogen and higher value of estrogen/progesterone ratio at $\mathrm{OV}$ can be related to increase of a high muscle stiffness and frequency in OV. Moreover, high hormone concentration of progesterone and relatively lower hormone concentration of estrogen were presented at LP and observed the lowest muscle stiffness and frequency. This might suggest that the highest both hormone level and lower ratio of estrogen/progesterone ratio at LP than other phases and this hormonal milieu influenced positively to decrease muscle stiffness and frequency of medial part. Since surge of progesteron is the highest around LP and progesterone has antiestrogenic physiological effect.

This area needs further investigation before definitive conclusions can be reached and in later studies, we compared the ratios of the medial and lateral muscle activities of the knee according to the MC. There are several limitations associated with our study. First of this study is that blood hormone concentrations is not measured, but we did determine menstrual phases by noninva- 
sively measuring basal body temperature. Secondly, the sample size may have been small, and further larger studies are required to confirm these results. In conclusion, the present study showed the highest muscle stiffness and frequency at $\mathrm{OV}$ and this might be due to the rapid increase of sole hormone in estrogen. Especially, medial part of quadriceps and hamstrings might be influenced during the MC with high concentration of estrogen at OV. Since there is different injury risk of muscle and ligament between menstrual phases, investigator should take this into consideration for the training program to avoid risk factor.

\section{CONFLICT OF INTEREST}

No potential conflict of interest relevant to this article was reported.

\section{REFERENCES}

Arendt EA, Agel J, Dick R. Anterior cruciate ligament injury patterns among collegiate men and women. J Athl Train 1999;34:86-92.

Beynnon BD, Shultz SJ. Anatomic alignment, menstrual cycle phase, and the risk of anterior cruciate ligament injury. J Athl Train 2008;43:541542.

Costill DL, Daniels J, Evans W, Fink W, Krahenbuhl G, Saltin B. Skeletal muscle enzymes and fiber composition in male and female track athletes. J Appl Physiol 1976;40:149-154.

de Mouzon J, Testart J, Lefevre B, Pouly JL, Frydman R. Time relationships between basal body temperature and ovulation or plasma progestins. Fertil Steril 1984;41:254-259.

Ditroilo M, Hunter AM, Haslam S, De Vito G. The effectiveness of two novel techniques in establishing the mechanical and contractile responses of biceps femoris. Physiol Meas 2011;32:1315-1326.

Duan XH, Allen RH, Sun JQ. A stiffness-varying model of human gait. Med Eng Phys 1997;19:518-524.

Dyer RF, Sodek J, Heersche JN. The effect of 17 beta-estradiol on collagen and noncollagenous protein synthesis in the uterus and some periodontal tissues. Endocrinology 1980;107:1014-1021.

Eiling E, Bryant AL, Petersen W, Murphy A, Hohmann E. Effects of menstrual-cycle hormone fluctuations on musculotendinous stiffness and knee joint laxity. Knee Surg Sports Traumatol Arthrosc 2007;15:126132.

Fischer GM. Comparison of collagen dynamics in different tissues under the influence of estradiol. Endocrinology 1973;93:1216-1218.

Fischer GM, Swain ML. Effect of sex hormones on blood pressure and vascular connective tissue in castrated and noncastrated male rats. Am
J Physiol 1977;232:H617-621.

Hama H, Yamamuro T, Takeda T. Experimental studies on connective tissue of the capsular ligament. Influences of aging and sex hormones. Acta Orthop Scand 1976;47:473-479.

Huston LJ, Wojtys EM. Neuromuscular performance characteristics in elite female athletes. Am J Sports Med 1996;24:427-436.

Irie T, Takahata M, Majima T, Abe Y, Komatsu M, Iwasaki N, Minami A. Effect of selective estrogen receptor modulator/raloxifene analogue on proliferation and collagen metabolism of tendon fibroblast. Connect Tissue Res 2010;51:179-187.

Janse de Jonge XA, Boot CR, Thom JM, Ruell PA, Thompson MW. The influence of menstrual cycle phase on skeletal muscle contractile characteristics in humans. J Physiol 2001;530(Pt 1):161-166.

Kubo K, Miyamoto M, Tanaka S, Maki A, Tsunoda N, Kanehisa H. Muscle and tendon properties during menstrual cycle. Int J Sports Med 2009:30:139-143.

Lebrun CM. The effect of the phase of the menstrual cycle and the birth control pill on athletic performance. Clin Sports Med 1994;13:419-441.

Lidström A, Ahlsten G, Hirchfeld H, Norrlin S. Intrarater and interrater reliability of Myotonometer measurements of muscle tone in children. J Child Neurol 2009;24:267-274.

Mercado-Simmen RC, Bryant-Greenwood GD, Greenwood FC. Relaxin receptor in the rat myometrium: regulation by estrogen and relaxin. Endocrinology 1982;110:220-226.

Oosthuyse T, Bosch AN. The effect of the menstrual cycle on exercise metabolism: implications for exercise performance in eumenorrhoeic women. Sports Med 2010;40:207-227.

Pisano F, Miscio G, Del Conte C, Pianca D, Candeloro E, Colombo R. Quantitative measures of spasticity in post-stroke patients. Clin Neurophysiol 2000;111:1015-1022.

Prince FP, Hikida RS, Hagerman FC. Muscle fiber types in women athletes and non-athletes. Pflugers Arch 1977;371:161-165.

Räsänen T, Messner K. Estrogen-dependent tensile properties of the rabbit knee medial collateral ligament. Scand J Med Sci Sports 2000;10:2027.

Sarwar R, Niclos BB, Rutherford OM. Changes in muscle strength, relaxation rate and fatiguability during the human menstrual cycle. J Physiol 1996;493(Pt 1):267-272.

Schantz P, Randall-Fox E, Hutchison W, Tydén A, Astrand PO. Muscle fibre type distribution, muscle cross-sectional area and maximal voluntary strength in humans. Acta Physiol Scand 1983;117:219-226.

Sung E, Han A, Hinrichs T, Vorgerd M, Manchado C, Platen P. Effects of follicular versus luteal phase-based strength training in young women. Springerplus 2014;3:668.

Wagner H, Blickhan R. Stabilizing function of antagonistic neuromuscu- 
loskeletal systems: an analytical investigation. Biol Cybern 2003;89:7179.

Wilkerson RD, Mason MA. Differences in men's and women's mean ankle ligamentous laxity. Iowa Orthop J 2000;20:46-48.

Yu WD, Panossian V, Hatch JD, Liu SH, Finerman GA. Combined effects of estrogen and progesterone on the anterior cruciate ligament. Clin Orthop Relat Res 2001;(383):268-281.

Zinder SM, Padua DA. Reliability, validity, and precision of a handheld myometer for assessing in vivo muscle stiffness. J Sport Rehabil 2011 Sep 6;Technical Notes 1. pii: 2010_0051. doi: 10.1123/jsr.2010-0051. 